\title{
Hepato-toxicological and lipid profile of male Wistar rats following chronic carbamazepine, gabapentin, and carbamazepine-gabapentin adjunctive treatment
}

\author{
*Osuntokun, O.S. ${ }^{1,2}$, Oladokun, O.O. ${ }^{1}$, Adedokun, K.I. ${ }^{1}$, Atere, T.G. ${ }^{3}$, Olayiwola, G. ${ }^{4}$, \\ Ayoka, A.O. ${ }^{2}$
}

\begin{abstract}
Aim: This study evaluated the hepatotoxicity and lipid profiles of male Wistar rats following chronic carbamazepine (CBZ), gabapentin (GBP) and carbamazepine-gabapentin (CBZ+GBP) adjunctive treatment.
\end{abstract}

Methods: Twenty-eight male Wistar rats were randomized into 4 groups $(n=7)$ to receive daily oral administration of normal saline $(0.2 \mathrm{ml})$, or CBZ $(25 \mathrm{mg} / \mathrm{kg})$, or GBP $(50 \mathrm{mg} / \mathrm{kg})$, or the sub-therapeutic dose of CBZ $(12.5 \mathrm{mg} / \mathrm{kg})$ and GBP $(25 \mathrm{mg} / \mathrm{kg})$ combination for 56 days. Thereafter, blood and liver homogenate were subjected to biochemical analysis, while liver tissues were processed for the histomorphological investigation. Data were analysed statistically, while $p<0.05$ was taken as level of significance.

Results: Activities of alanine phosphatase and aspartate aminotransferase significantly increased in the $\mathrm{CBZ}$ and $\mathrm{CBZ}+\mathrm{GBP}$ treated rat. $\mathrm{CBZ}$ and $\mathrm{CBZ}+\mathrm{GBP}$ treatments increased the plasma concentration of low-density lipoprotein and total cholesterol. The liver concentration of malondialdehyde increased significantly in all the treated groups relative to control. There were severe vascular congestions in the liver of the CBZ treated rats, this was moderate in the GBP and CBZ + GBP treated rats.

Conclusion: Chronic use of CBZ may induce hepatotoxicity and lipid profile derangement, GBP and $\mathrm{CBZ}+\mathrm{GBP}$ adjunctive treatment may be saver than treatment with CBZ.

Keywords: Anticonvulsants; Carbamazepine; Gabapentin; Carbamazepine-gabapentin; Hepatotoxicity.

\author{
*Corresponding author \\ Osuntokun, O.S. \\ ORCID-NO: http://orcid.org/0000-0002-0780-8729 \\ Email: opeyemi.osuntokun@uniosun.edu.ng
}

\footnotetext{
${ }^{1}$ Department of Physiology, Faculty of Basic Medical Sciences, College of Health Sciences, Osun State University Osogbo, Nigeria

${ }^{2}$ Department of Physiological Sciences, Faculty of Basic Medical Sciences, College of Health Sciences, Obafemi Awolowo University, Ile-Ife, Nigeria

${ }^{3}$ Department of Medical Biochemistry, Faculty of Basic Medical Sciences, College of Health Sciences, Osun State University Osogbo, Nigeria

${ }^{4}$ Department of Clinical Pharmacy and Pharmacy Administration, Faculty of Pharmacy, Obafemi Awolowo University, Ile-Ife, Nigeria
} 


\title{
Profil hépato-toxicologique et lipidique de rats Wistar mâles après un traitement d'appoint chronique à la carbamazépine, à la gabapentine et à la carbamazépine-gabapentine
}

\author{
*Osuntokun, O.S. ${ }^{1,2}$, Oladokun, O.O. ${ }^{1}$, Adedokun, K.I. ${ }^{1}$, Atere, T.G. ${ }^{3}$, Olayiwola, G. ${ }^{4}$, \\ Ayoka, A.O. ${ }^{2}$
}

\section{Resume}

Objectif: Cette étude a évalué l'hépatotoxicité et les profils lipidiques de rats Wistar mâles après un traitement d'appoint chronique à la carbamazépine (CBZ), à la gabapentine (GBP) et à la carbamazépinegabapentine (CBZ+GBP).

Méthodes: Vingt-huit rats Wistar mâles ont été randomisés en 4 groupes $(n=7)$ pour recevoir une administration orale quotidienne de solution saline normale $(0,2 \mathrm{ml})$, ou CBZ $(25 \mathrm{mg} / \mathrm{kg})$, ou GBP (50 $\mathrm{mg} / \mathrm{kg})$, ou la dose sous-thérapeutique de l'association CBZ $(12,5 \mathrm{mg} / \mathrm{kg})$ et GBP $(25 \mathrm{mg} / \mathrm{kg})$ pendant 56 jours. Par la suite, le sang et l'homogénat de foie ont été soumis à une analyse biochimique, tandis que les tissus du foie ont été traités pour l'étude histomorphologique. Les données ont été analysées statistiquement, tandis que $\mathrm{p}<0,05$ a été pris comme niveau de signification.

Résultats: Les activités de l'alanine phosphatase et de l'aspartate aminotransférase ont augmenté de manière significative chez les rats traités par $\mathrm{CBZ}$ et $\mathrm{CBZ}+\mathrm{GBP}$. Les traitements $\mathrm{CBZ}$ et CBZ + GBP ont augmenté la concentration plasmatique des lipoprotéines de basse densité et du cholestérol total. La concentration hépatique de malondialdéhyde a augmenté de manière significative dans tous les groupes traités par rapport au témoin. Il y avait des congestions vasculaires sévères dans le foie des rats traités par $\mathrm{CBZ}$, ceci était modéré chez les rats traités par GBP et CBZ + GBP.

Conclusion: L'utilisation chronique de CBZ peut induire une hépatotoxicité et un trouble du profil lipidique, le traitement d'appoint GBP et CBZ + GBP peut être plus économique que le traitement par CBZ.

Mots-clés: Anticonvulsivants, Carbamazépine, gabapentine, Carbamazépine-gabapentine, Hépatotoxicité.

*Corresponding author

Osuntokun, O.S.

ORCID-NO: http://orcid.org/0000-0002-0780-8729

Email: opeyemi.osuntokun@uniosun.edu.ng

\footnotetext{
${ }^{1}$ Department of Physiology, Faculty of Basic Medical Sciences, College of Health Sciences, Osun State University Osogbo, Nigeria

${ }^{2}$ Department of Physiological Sciences, Faculty of Basic Medical Sciences, College of Health Sciences, Obafemi Awolowo University, Ile-Ife, Nigeria

${ }^{3}$ Department of Medical Biochemistry, Faculty of Basic Medical Sciences, College of Health Sciences, Osun State University Osogbo, Nigeria

${ }^{4}$ Department of Clinical Pharmacy and Pharmacy Administration, Faculty of Pharmacy, Obafemi Awolowo University, Ile-Ife, Nigeria
}

Research Journal of Health Sciences subscribed to terms and conditions of Open Access publication. Articles are distributed under the terms of Creative Commons Licence (CC BY-NC-ND 4.0). (http://creativecommons.org/licences/by-nc-nd/4.0).

http://dx.doi.org/10.4314/rejhs.v9i3.10 


\section{INTRODUCTION}

The global burden of epilepsy disorder is becoming increasingly worrisome. The World Health Organisation (WHO) estimated 49.5 million individuals with active epilepsy (1). Often time, conventional antiepileptic drugs (AEDs) remain the first line of treatment in epilepsy but refractory epileptic seizures are poorly controlled in about 25-30 percent of epileptic patients depending on the level of resistance to some conventional AEDs. This has repeatedly informed the choice of combination therapy or adjunctive treatment of two different AEDs with varying mechanisms of action (2). Findings from experimental and clinical studies have shown that rational combination of a conventional AED, for example, carbamazepine with a novel antiepileptic, gabapentin can be more efficacious in the termination of convulsion indices than individual drug treatment ( 3 and 4$)$.

Carbamazepine $(5 \mathrm{H}$-dibenzo $[b$, $f$ ]azepine-5-carboxamide), a conventional anticonvulsant has been reportedly efficacious in the treatment of partial seizures with complex symptomatology (psychomotor, temporal lobe); generalized tonic-clonic seizures (grand mal); and mixed-seizure patterns (5). This drug has been implicated in the reduction of polysynaptic responses and blocking post-tetanic potentiation, while the anticonvulsant activity has been attributed to the blockade of voltage-sensitive sodium channels (6).

Gabapentin (1-aminoethyl, cyclohexane acetic acid) is an approved adjunctive agent by the Food and Drug Agency (FDA) of the United State of America for the treatment of partial and secondary generalized convulsion. Being a lipophilic compound, it was designed structurally as an analogue of gamma-aminobutyric acid (GABA) by the addition of a cyclohexyl moiety to its backbone, thus possessing a very high tendency to cross the blood-brain barrier with resultant centrally-acting effects (7). However, the mechanisms of action of gabapentin remain vague. Previous reports in the literature have shown that gabapentin neither binds to $\mathrm{GABA}_{\mathrm{A}}$ or $\mathrm{GABA}_{\mathrm{B}}$ receptors nor is it metabolized to GABA $(8,9)$. Besse et al. $(10)$ reported the inhibitory activities of gabapentin on the GABAcatabolizing enzyme, GABA-transaminase (GABA-T), thus increasing the concentration of the inhibitory neurotransmitter GABA (11). Gabapentin has also been implicated in the inhibition of neuronal calcium influx (12), binding to $\alpha_{2} \delta$ calcium channel subunits (13) and activation of glutamate dehydrogenase (14).

While carbamazepine is a liver-enzyme inducing AED with high protein binding property which undergoes oxidation via CYP $3 \mathrm{~A} 4$ and to a lesser extent CYP 2C8 to carbamazepine-10,11epoxide as active metabolite with potential toxicity, gabapentin has no capacity to induce liver enzymes with little or no hepatotoxic effect (15) which makes it considerably suitable for adjunctive treatment with CBZ (4).

Findings from our previous study revealed that carbamazepine, gabapentin, and gabapentin-carbamazepine combination decimated the serum concentration of testosterone, decreased the absolute weight of the testis, epididymis, and seminal vesicle in addition to alteration of seminal profile and histoarchitecture of testicular tissue (16). However, liver remains the major catabolic organ and it is therefore expedient to determine its functions vis-à-vis the toxicological profile of carbamazepine, gabapentin, or carbamazepinegabapentin adjunctive treatment, hence this study.

\section{MATERIALS AND METHODS Chemicals}

The Potassium hydroxide, Ethylene diamine tetraacetate (EDTA), Carbon tetrachloride, Dipotassium hydrogen phosphate, Tris buffer, Triton-X100, Potassium dihydrogen phosphate, Methanol, Alcohol, Trichloroacetic acid, Chloroform, Thiobarbituric acid, Sodium hydroxide, Sodium chloride, 5',5'-dithiol (bis)-2nitrobenzoic acid, standard reduced glutathione were purchased from either Sigma, USA or Merck limited, Mumbai, India.

\section{Animals selection and care}

This study utilized total of 28 male Wistar rats $(160-180 \mathrm{~g})$. The rats were procured from the animal house of the College of Health Sciences, Osun State University, Osogbo. Standard rodents 'diet (manufactured by Ground Cereals Nigeria limited) and water were supplied to them ad libitum. The approval to carry out this experimental research was obtained from the Health Research Ethical Committee (HREC) of the Osun State University, Osogbo, Nigeria. After 2 weeks acclimatization, the animals were randomly shared into 4 groups $(n=7)$ : group I (control) received normal saline $(0.2 \mathrm{ml}$ per oral [P.O]), group II received CBZ $(25 \mathrm{mg} / \mathrm{kg} \mathrm{BW}$ P.O]) (17), group III received GBP $(50 \mathrm{mg} / \mathrm{kg} \mathrm{BW}$ P.O) (18) while group IV received the subtherapeutic dose (adjunctive treatment) of CBZ $(12.5 \mathrm{mg} / \mathrm{kg}$ P.O) and GBP $(25 \mathrm{mg} / \mathrm{kg})$. This treatment lasted for 56 consecutive days. 


\section{Animals sacrifice and collection of tissues}

Twenty-four hours after the last dose of treatment, the animals were euthanized by cervical dislocation, the blood was collected via cardiac puncture into an EDTA bottle, while the liver was isolated for weight determination.

\section{Homogenization of liver}

The liver from each animal was macerated by cutting about $1.5 \mathrm{~g}$ tissue of the liver organ, washed in physiological solution, followed by immediate homogenization in the ice-cold buffer $(0.25 \mathrm{M}$ sucrose, $1 \mathrm{mM}$ EDTA, and $1 \mathrm{mM}$ Tris- $\mathrm{HCl}, \mathrm{pH}$ 7.4) and then subjected to cold centrifuge at $3000 \mathrm{rpm}$ for ten minutes. The supernatant collected was stored $\left(-20^{\circ} \mathrm{C}\right)$ for the evaluation of the liver enzymes and concentration of malondialdehyde according to the method of Tsikas (19).

\section{Biochemical assessment}

Activities of liver enzymes such as alkaline phosphatase (ALP), alanine aminotransferase (ALT) and aspartate aminotransferase (AST) were determined in the supernatant of the liver tissue using lipid profile such as total cholesterol (TC), triglyceride (TG), high-density lipoprotein-cholesterol (HDL), and low-density lipoprotein (LDL) were determined in the plasma using Randox assay kits (Sigma, USA) using the enclosed protocols.

\section{Histomorphological study}

The liver tissue of each experimental group was processed according to the method of Tsikas et al (19). The processed tissues were stained with haematoxylin and eosin ( $\mathrm{H}$ and $\mathrm{E})$ and thereafter subjected to a Leica microscope for the evaluation of any sign(s) of morphological alteration.

\section{Statistical analysis}

Data were subjected to graph pad prism version 5.01 for suitable statistical analyses. The statistically calculated data were further expressed as mean \pm SEM. 'T' test was used to compare between the means of two experimental groups, means across the groups were subjected to analysis of variance (ANOVA), and StudentNewman-Keuls post hoc analysis, while $\mathrm{p}<0.05$ was taken as the level of significance.

\section{RESULTS}

Relative liver weight following carbamazepine, gabapentin, and carbamazepine-gabapentin adjunctive treatments

There was significant decrease in the relative weight of the liver in the $\mathrm{CBZ}$ treated rats (3.32 \pm 0.18$)$ compared with the control (4.33 \pm $0.20)(\mathrm{t}=3.75 \mathrm{df}=4)$, while neither GBP $(4.23 \pm$ $0.14)$ nor $\mathrm{CBZ}+\mathrm{GBP}$ adjunctive treatment (4.16 \pm 0.13 ) had significant effect on the relative liver weight compared with control $(\mathrm{t}=0.438 \mathrm{df}=4)$ and $(\mathrm{t}=0.74 \mathrm{df}=4)$ respectively. However, there was a significant difference in the relative liver weight in the GBP and CBZ + GBP adjunctive treatment $(\mathrm{t}=3.95 \mathrm{df}=4)$ and $(\mathrm{t}=3.72 \mathrm{df}=4)$ respectively compared with the CBZ treated rats, while there was no difference between GBP and CBZ + GBP adjunctive treatment $(\mathrm{t}=0.37 \mathrm{df}=4)$.

Liver enzymes activity following chronic carbam aze pine, gabapentin, and carbamazepine-gabapentin adjunctive treatment

In this study, there was significant increase in the activities of ALP in the tissue of CBZ and CBZ + GBP treated groups (35.2 \pm $0.959)$ and $(24.4 \pm 0.602)$ respectively compared with the control $(18.9 \pm 0.915)(\mathrm{p}=$ 0.0001 and $\mathrm{F}=83.0$ ). However, GBP treatment $(20.7 \pm 0.667)$ had no significant effect on the activities of ALP compared with control $(\mathrm{t}=1.53$ $\mathrm{df}=4$ ). The activities of ALP in the GBP and CBZ + GBP treated groups significantly decreased compared with CBZ treatment group $(\mathrm{t}=12.4$ $\mathrm{df}=4)$ and $(\mathrm{t}=9.55 \mathrm{df}=4)$ respectively. Moreover, activities of ALP in the CBZ + GBP increased significantly relative to GBP treated group $(\mathrm{t}=4.12 \mathrm{df}=4)$. Concerning the activities of ALT, there was no significant change across the treatment groups compared with control $(\mathrm{p}=$ $0.9901 ; \mathrm{F}=0.0362)$.

Following long term CBZ administration, there was significant increase in the activities of AST $(67.7 \pm 1.210)$ compared with control $(58.3 \pm 1.160)(\mathrm{t}=5.62 \mathrm{df}=4)$ while the activities of this enzyme remained unchanged in the GBP $(57.3 \pm 1.510)$ and CBZ + GBP treated groups $(59.6 \pm 0.364)$ relative to their control counterpart $(\mathrm{t}=0.483 \mathrm{df}=4)$ and $(\mathrm{t}=1.08 \mathrm{df}=4)$ respectively. Moreover, AST activities significantly decreased in GBP and CBZ + GBP treatment groups compared with $\mathrm{CBZ}$ alone treatment $(\mathrm{t}=5.34 \mathrm{df}=4)$ and $(\mathrm{t}=6.41 \mathrm{df}=4)$ respectively, while there was no significant change in the activities of AST between GBP and $\mathrm{CBZ}+\mathrm{GBP}(\mathrm{t}=1.43 \mathrm{df}=4)$. 
Lipid profile of male Wistar rats following chronic carbamazepine, gabapentin, and carbamazepine-gabapentin adjunctive treatment

This study determined the effects of CBZ, GBP and CBZ + GBP on some of the lipid profile of male Wistar rats. In this study, there was significant increase in the level of LDL in CBZ and CBZ + GBP treated rats $(84.4 \pm 0.643)$ and $(79.9 \pm 0.737)$ respectively compared with control (74.7 \pm 0.561$)(\mathrm{p}=0.0001 ; \mathrm{F}=42.3)$, while there was no significant change between GBP treated rats $(77.0 \pm 0.618)$ and the control $(\mathrm{t}=2.72 \mathrm{df}=4)$. However, there was significant decline in the level of LDL in the GBP and CBZ+ GBP treated rats compared with CBZ treatment group $(\mathrm{t}=8.32 \mathrm{df}=4)$ and $(\mathrm{t}=4.63 \mathrm{df}=4)$ respectively. A significant increase was also observed in the $\mathrm{CBZ}+\mathrm{GBP}$ treated rats compared with GBP alone treated group $(t=3.01$ $\mathrm{df}=4)$.

In this study, CBZ treatment significantly decreased the level of HDL (113 \pm 1.24) compared with control $(118 \pm 0.93)(\mathrm{t}=2.92$ $\mathrm{df}=4$ ), while this was unchanged in the GBP and CBZ + GBP treated groups $(118 \pm 0.723$ and (115 $\pm 0.93)$ respectively relative to their control counterpart $(\mathrm{t}=0.305 \mathrm{df}=4)$ and $(\mathrm{t}=2.37 \mathrm{df}=4)$. However, HDL concentration significantly increased in GBP treated rats compared with CBZ treated $(\mathrm{t}=2.90 \mathrm{df}=4)$, while $\mathrm{CBZ}+\mathrm{GBP}$ treated rats had no significant difference relative to GBP alone treatment group $(\mathrm{t}=0.92 \mathrm{df}=4)$.

Concerning the level of total cholesterol, $\mathrm{CBZ}$ and $\mathrm{CBZ}+\mathrm{GBP}$ treatments significantly increased the level of TC $(214 \pm 2.75)$ and $(187 \pm$ $1.05)$ respectively compared with the control $(163 \pm 2.280)(p=0.0001 ; F=99.6)$ while GBP treatment had no significant effect on the level of TC $(166 \pm 2.850)$ compared with control $(\mathrm{t}=0.56$ $\mathrm{df}=4$ ). However, the serum level of $\mathrm{TC}$ significantly decreased in GBP and CBZ + GBP treated groups compared with $\mathrm{CBZ}$ alone treatment $(\mathrm{t}=12.1 \mathrm{df}=4)$ and $(\mathrm{t}=8.93 \mathrm{df}=4)$ respectively. Moreover, the level of TC significantly increased in CBZ + GBP treatment group compared with GBP alone treated rats $(\mathrm{t}=7.18 \mathrm{df}=4)$.

In this study, $\mathrm{CBZ}, \mathrm{GBP}$ or $\mathrm{CBZ}+\mathrm{GBP}$ treatment had no significant effect on the serum level of TG $(784 \pm 2.72),(774 \pm 1.31)$ or $(776 \pm$ $1.33)$ respectively $(\mathrm{p}=0.1575 ; \mathrm{F}=2.27)$. However, GBP treatment significantly increased the level of TG compared with the CBZ treatment group $(\mathrm{t}=3.58 \mathrm{df}=4)$, while there was no significant change between the $\mathrm{CBZ}+\mathrm{GBP}$ treated and $\mathrm{CBZ}$ treated rats $(\mathrm{t}=2.72 \mathrm{df}=4)$. Also, there was no significant change in the serum level of TG between GBP and CBZ + GBP treatment groups $(\mathrm{t}=1.38 \mathrm{df}=4)$.

Effects of carbamazepine, gabapentin and carbamazepine-gabapentin adjunctive treatment on lipid peroxidation (malondialdehyde) in the liver of male Wistar rats

There was significant increase in the level of MDA following CBZ, GBP and CBZ + GBP treatments $(5.14 \pm 0.26),(2.50 \pm 0.28)$ and $(2.78 \pm 0.43)$ respectively compared with control $(1.05 \pm 0.21)(p=0.0001 ; F=31.2)$. However, the tissue level of MDA significantly decreased in GBP and CBZ + GBP treated groups compared with $\mathrm{CBZ}$ treated rats $(\mathrm{t}=6.98 \mathrm{df}=4)$ and $(\mathrm{t}=4.74$ $\mathrm{df}=4$ ) respectively, while there was no significant difference between the tissue level of MDA in $\mathrm{GBP}$ and $\mathrm{CBZ}+\mathrm{GBP}$ treatment groups $(\mathrm{t}=0.557$ $\mathrm{df}=4)$.

Histomorphological profile of the liver following chronic carbamazepine, gabapentin and carbamazepine-gabapentin adjunctive treatment in male Wistar rats

The histomorphological profile of the liver, particularly CBZ treatment representative rats revealed severe vascular congestion (red arrow). However, this congestion was moderate in the GBP and CBZ + GBP representative slides. In the $\mathrm{CBZ}+\mathrm{GBP}$ treated representative rat, there are abundant sinusoid lining cells; the sinusoids are not congested; the hepatocytes are showing normal histological features. The liver section is with preserved and well-defined hepatic profile.

\section{DISCUSSION}

The liver is one of the most vulnerable organs to xenobiotic-induced toxicity. This is not unrelated to the fact that this vital organ remains the initial site of contact for many orally ingested therapeutic agents. The pathogenesis of most drug-induced liver injuries is initiated by the metabolic conversion of drugs into a reactive intermediate metabolite, for example, carbamazepine-10,11-epoxide has been implicated as the cause of fatality due to liver toxicity and neurotoxicity following either an overdose or lower doses of carbamazepine $(21,22)$. This is owing to the strong affinity of both the parent compound and metabolite to plasma proteins (23). Combination of two or more AEDs of varying mechanism, of action, remains one of the best approaches to refractory epileptic seizure and required for a long term (23) but not devoid of neurotoxicity and other 
reproductive dysfunctions $(17,24)$. Hence it is very crucial to determine experimentally, the toxicological impact of carbamazepinegabapentin adjunctive treatment on the liver.

While GBP administration did not affect the liver weight, CBZ treatment significantly decreased the liver weight. This is not unrelated to the potential toxicity of the drug CBZ. This finding is in line with the previous report of Jabar and Al-Bakri (25) who reported the potential adverse effects of CBZ on the liver weight and morphology after a short- term treatment. It would be recalled that in this study the drugs were administered chronically for 56 consecutive days which could have made the damage to have been more pronounced in this study than the report of Jabar and Al-Bakri (25). However, findings from this study suggest a greater tolerance by the rats to $\mathrm{CBZ}+\mathrm{GBP}$ adjunctive treatment than CBZ alone. This was evident as CBZ + GBP adjunctive treated rats had a significantly higher body and liver weight compared to $\mathrm{CBZ}$ alone treated group.

It is a known fact that liver enzymes (aspartate aminotransferase, alanine aminotransferase) or maker of obstruction in the bile flow cholestasis (alkaline phosphatase or gamma-glutamyl transferase) are all susceptible to alteration following AEDs treatment which could therefore serve as an indicator of hepatocellular toxicity/injury (22). In a similar study, Iida (26) attributed the activities of these liver enzymes to carbamazepine with resultant induction of microsomal hepatic enzymes. In this study, CBZ alone at $25 \mathrm{mg} / \mathrm{kg} \mathrm{BW}$ has slightly increased the activity of ALP and AST which may be due to the higher dose in the CBZ group compared to the combination group. A significant rise in the activities of ALP sequel to CBZ alone and $\mathrm{CBZ}+\mathrm{GBP}$ adjunctive treatment could serve as a pointer to the hepatotoxic effects of CBZ either in monotherapy or adjunctive treatment, while the ALP activities remained unchanged in GBP treated group. An assertion that GBP treatment is saver than $\mathrm{CBZ}$ or $\mathrm{CBZ}+\mathrm{GBP}$ adjunctive treatment.

Surprisingly, none of the treatment drugs in this study affected the ALT and AST activities except CBZ alone whose chronic administration triggered a significant increase in the activities of AST, but this was ameliorated in CBZ + GBP adjunctive treatment compared with $\mathrm{CBZ}$ alone treated group. This is a shred of suggestive evidence that hepatocellular toxicity following either CBZ alone or CBZ + GBP adjunctive treatment, as recorded in this study is unrelated to
ALT activities. Findings in this study are consistent with the previous report of (22), that carbamazepine is one of the conventional hepatotoxic AEDs, whose toxic effect can lead to death or acute liver failure which could imperatively require liver transplantation. The mechanism of derangement in the liver toxicity may be linked to the production of reactive toxic metabolite or because of the induction of immune allergic reactions $(23,24)$ which might have eventually resulted in the enormous release of the end product of lipid peroxidation, malondialdehyde.

Blood concentration of certain lipids and lipoproteins have been reportedly affected by several AEDs with resultant effects in the development of coronary heart disease in later life (27) because AEDs therapy is a life-long affair. A significant increase in the plasma concentration of LDL and TC following CBZ and $\mathrm{CBZ}+\mathrm{GBP}$ adjunctive treatment is a suggestive indication that $\mathrm{CBZ}$ alone or its adjunctive use can pose a cardiovascular risk (hyperlipidemia) on its user. Interestingly, this risk may be mild or moderate in the CBZ + GBP adjunctive treatment relative to $\mathrm{CBZ}$ alone treatment while GBP remains the safest among the trios treatment group as it is evident in this study.

Excessive increase in the level of total cholesterol following CBZ treatment could be linked with its hepatic cytochrome $\mathrm{P} 450$ enzymes inducing properties. Mantel-Teeuwisse et al. (28) suggested a competition for binding space on this liver enzyme between the AEDs and cholesterol with the resultant decrease in the breakdown of cholesterol to bile acids and eventually, giving rise to an increase in the level of TC. Moreover, this study is consistent with the previous report of Jakubus et al. (29), who showed an increase in TC and LDL levels after chronic CBZ treatment.

In this study, severe vascular congestion following CBZ treatment is an assertion that the said drug tends to alter the lipid profile. Interestingly, this was reduced in the CBZ + GBP treated group. An indication that $\mathrm{CBZ}+\mathrm{GBP}$ is better tolerated than CBZ alone. This is not unrelated to the reduction in the two drugs (CBZ + GBP) at the sub-therapeutic dose combined as an adjunctive treatment. However, this finding is in agreement with the study of Higuchi et al. (2012) that repeated administration of CBZ is necessary for the establishment of liver injury. Surprisingly, findings from our similar study (16) showed significant restoration of normal reproductive parameters twenty after twentyeight days of drug withdrawal. 
This study, therefore, concludes that an optimum carefulness is required by the neurologists and their clients in the prescription and use of antiepileptic drugs, especially CBZ. However, adjunctive use of CBZ + GBP may be safer than $\mathrm{CBZ}$ alone treatment, while GBP alone treatment remains the safest among the three treatment pattern.

Grant information: The authors declared that this research was self-sponsored and conducted in the absence of any commercial or financial relationships that could be construed as a potential confiict of interest.

Acknowledgement: The authors acknowledge the technical contributions of Miss Awonuga M.A.M and Miss Salam A.M of the Physiology Laboratory Unit, Osun State University, Osogbo.

\section{References}

1. Beghi E., Giussani G, Nichols E., AbdAllah F., Abdela J., Abdelalim A., Abraha H.N., Adib M.G., Agrawal S., Alahdab F., Awasthi A., Ayele Y., Barboza M.A., Belachew A.B., Biadgo B., Bijani A., Bitew ., Carvalho F., Chaiah Y., Daryani A., Do H.P., Dubey M., Endries A.Y.Y., Eskandarieh S., Faro A., Farzadfar F., Fereshtehnejad S.M., Fernandes E., Fijabi E.O., Filip I., Fischer F., Gebre A.K., Tsadik A.G., Gebremichael T.G., Gezae K.E., GhasemiKasman M., Weldegwergs K.G., Degefa M.G., Gnedovskaya E.V., Hagos T.B., HajMirzaian A., HajMirzaian A., Hassen H.Y., Hay S.I., Jakovljevic M., Kasaeian A., Kassa T.D., Khader Y.S., Khalil I., Khan E.H., Khubchandani J., Kisa A., Krohn K.J., Kulkarni C., Nirayo Y.L., Mackay M.T., Majdan M., Majeed M., Manhertz T., Mehndiratta M.M., Mekonen T., Meles H.G., Mengistu G., Mohammed S., Naghavi M., Mokdad A.H., Mustafa G., Irvani S.S.N., Nguyen L.H., Nixon M.R., OgboF.A., Olagunju A.T., Olagunju T.O., Owolabi M.O., Phillips M.R., Monsalve G.D.P., Qorbani M., Radfar A., Rafay A., Movaghar F.R., Reinig N., Sachdev P.S., Safari H., Safari S., Sahraian M.A., Samy A.M., Sarvi S., Sawhney M., Shaikh M.A., Sharif M., Singh G., Smith M., Szoeke C.E.I., Seisdedos R.T., Temsah M.H., Temsah O., Girbés M.T., Tran B.X., Tsegay A.A.T., Ullah I., Venketasubramanian N., Westerman R., Winkler A.S., Yimer E.M., Yonemoto N., Feigin V.L., Vos $\mathrm{T}$ and Murray C.J.L (2019). The Lancet Neurology 18: 357-75

2. Das N., Dhanawat M and Shrivastav S.K (2012). An overview on antiepileptic drugs. Drug Discoveries \& Therapeutics 6(4):178-193.

3. Prisco L., Ganau M., Bigotto F and Zornada F (2011). Trigeminal neuralgia: successful antiepileptic drug combination therapy in three refractory cases. Drug, healthcare and patient safety 3: 43-45.

4. Olaibi O.K., Osuntokun O.S., Ijomone O.M (2014). Effects of chronic administration of gabapentin and carbamazepine on the histomorphology of the hippocampus and striatum. Annals of Neurosciences 21 (2): 57-61.

5. Goldenberg M.M (2010). Overview of Drugs Used for Epilepsy and Seizures; Etiology, Diagnosis, and Treatment. Pharmacy and Therapeutics 35(7): 392-415.

6. Lang D.G., Wang C.M and Cooper B.R (1993). Lamotrigine, phenytoin, and carbamazepine interactions on the sodium current present in N4TG1 mouse neuroblastoma cells. Journal of Pharmacology, Experiment and Therapeutics 266:829-835.

7. Honarmand A., Safavi M and Zare M (2011). Gabapentin: an update of its pharmacological properties and therapeutic use in epilepsy. Journal of Research in Medical Sciences 16:1062-1069.

8. Cai K., Nanga R. P. R., Lamprou L., Schinstine C., Eliott M and Hariharan H (2012). The impact of gabapentin administration on brain GABA and glutamate concentrations: a 7T 1H-MRS study. Neuropsychopharmacology 37: 2764-2771

9. Kammerer M., Rassner M.P., Freiman T.M and Feuerstein TJ (2011). Effects of antiepileptic drugs on GABA release from rat and human neocortical synaptosomes. Naunyn Schmiedebergs Archives of Pharmacology 384:47-57.

10. Besse A., Wu P., Bruni F., Donti T., Graham B.H., Craigen W.J., McFarland R., Moretti P., Lalani S., Scott K.L and Taylor R.W (2015). The GABA Transaminase, ABAT, Is essential for Mitochondria Nucleoside Metabolism. Cell Metabolism 21 (3): 417-427.

11. Loscher W., Honack D and Taylor C.P (1991). Gabapentin increases aminooxy acetic acidinduced GABA accumulation in several regions of the rat brain. Neuroscience Letter 128:150-154.

12. Patel R and Dickenson A. H. (2016). Mechanisms of the gabapentinoids and $\alpha 2 \delta$-1 calcium channel subunit in neuropathic pain. Pharmacology research and perspectives 4(2): e00205.

13. Cassidy JS, Ferron L, Kadurin I, Pratt WS, Dolphin AC (2014). Functional exofacially tagged N-type calcium channels elucidate the interaction with auxiliary $\alpha 2 \delta$-1 subunits. Proceedings of National Academics of Sciences of United State of America 111: 8979-8984.

14. Meyerhoff D.J., Murray D.F., Durazzo T.C and Pennington D.L (2018. Brain GABA and Glutamate Concentrations Following Chronic Gabapentin Administration: A Convenience Sample Studied During Early Abstinence from Alcohol. Frontiers in Psychiatry 9: 1-78.

15. Al Khalili Y and Jain S (2020). Carbamazepine Toxicity. StatPearls Publishing; 2020 JanA v a i l a ble f $\mathrm{r}$ o m : 
https://www.ncbi.nlm.nih.gov/books/NBK5078 $52 /$

16. Osuntokun O.S., Olayiwola G., Oladele A., Ola I., Ayoka A.O (2017). Chronic administration of gabapentin and a gabapentincarbamazepine combination reversibly suppress testicular function in male Wistar rats (Rattus norvegicus). Pathophysiology 24: 63-69.

17. Martins I.L., Nunes J., Charneira C., Morello J., Pereira S.A., Telo J.P., Marques M.M and Antunes A.M.M (2018). The first-line antiepileptic drug carbamazepine: Reaction with biologically relevant free radicals. Free Radical in Biology and Medicine 129:559-568.

18. Lin YJ, Lee YHP, Ravis WR (2013) Effects of Short-Term Treatment with Recombinant Human Growth Hormone on Carbamazepine Pharmacokinetics in Rats. Clinical and Experimental Pharmacology 3: 132.

19. Baydas G, Sonkaya E, Tuzcu M, Yasar A and Donder E (2005). Novel role for gabapentin in neuroprotection of central nervous system in streptozotocine-induced diabetic rats. Acta Pharmaceutica Sinica B 26(4):417-422.

20. Tsikas D (2017). Assessment of lipid peroxidation by measuring malondialdehyde (MDA) and relatives in biological samples: Analytical and biological challenges. Analytical Biochemistry 524: 13-30.

21. Dassarmaa B., Nand D.K., Gangopadhyay S and Samanta S (2018). Hepatoprotective effect of food preservatives (butylated hydroxyanisole, butylated hydroxytoluene) on carbon tetrachloride-induced hepatotoxicity in rats. Toxicology Reports 5: 31-37.

22. Kanousil N.L and Gidal B.E (2012). Antiepileptic Drugs. In: Mozayani A., Raymon L. (eds) Handbook of Drug Interactions. Humana Press.
23. Hussein R.R.S., Soliman R.H., Ali A.M.A., Tawfeik M.H and Abdelrahim M.E.A (2013). Effect of antiepileptic drugs on liver enzymes. Beni-Suef University Journal of Basic and Applied Sciences 2 (2013): 14 e1 9.

24. Lee WM (2003). Drug-induced hepatotoxicity. New England Journal of Medicine. 349(5):474e85.

25. Bjornsson E (2008). Hepatotoxicity associated with antiepileptic drugs. Acta Neurologica Scandinavica 118(5): 281e90.

26. Jaber and Al-Bakri, N.A (2018). Tegretol (Carbamazepine) Effect on the Morphometric Assay of Liver in Female White Mice (Mus musculus). Ibn AL- Haitham Journal for Pure and Applied Science 1 (31): 1-9.

27. Iida A., Sasaki E., Yano A., Tsuneyama K., Fukami T., Nakajima M and Yokoi T (2015). Hepatotoxicity by Carbamazepine Requires Metabolism in Rats Drug Metabolism and Disposition 43 (7) 958-968

28. Manimekalai K., Visakan B.., Salwe K.J and Murugesan S (2014). Evaluation of Effect of Antiepileptic Drugs on Serum Lipid Profile among Young Adults with Epilepsy in a Tertiary Care Hospital in Pondicherry. Journal of Clinical and Diagnostic Research 8(8): HC05-HC09.

29. Mantel-Teeuwisse A.K., Kloosterman J.M., Maitland-van der Zee A.H., Klungel O.H., Porcius A.J, and de- Boer A (2001). DrugInduced lipid changes: a review of the unintended effects of some commonly used drugs on serum lipid levels. Drug safety 24(6):443-456.

30. Jakubus T., Michalska-Jakubus M., Lukawski K., Janowska A and Czuczwar S.J (2009). Atherosclerotic risk among children taking antiepileptic drugs. Pharmacological reports 61(3):411-423.

How to cite this article:

Osuntokun, O.S., Oladokun, O.O., Adedokun, K.I., Atere, T.G., Olayiwola, G., Ayoka, A.O. Hepato-toxicological and lipid profile of male Wistar rats following chronic carbamazepine, gabapentin, and carbamazepine-gabapentin adjunctive treatment. Research Journal of Health Sciences, 2021, 9(3): 289-298 
Table 1. Liver enzymes activity following chronic carbamazepine, gabapentin, and carbamazepine-gabapentin adjunctive treatment

\begin{tabular}{llll}
\hline Treatment group & ALP (U/L) & ALT (U/L) & AST (U/L) \\
\hline Control & $18.9 \pm 0.92$ & $75.7 \pm 0.70$ & $58.3 \pm 1.16$ \\
CBZ & $35.2 \pm 0.96^{\beta}$ & $76.2 \pm 1.32$ & $67.7 \pm 1.21^{\beta}$ \\
GBP & $20.7 \pm 0.67^{\delta}$ & $76.0 \pm 1.10$ & $57.3 \pm 1.51^{\delta}$ \\
CBZ + GBP & $24.4 \pm 0.60^{\beta \delta \pi}$ & $75.9 \pm 1.40$ & $59.6 \pm 0.36^{\delta}$ \\
\hline$\beta=$ Significant increase compared with $\operatorname{control}(\mathrm{p}=0.005)$ & & \\
$\delta=$ Significant decrease compared with CBZ $(\mathrm{p}=0.006)$ & & \\
$\pi=$ Significant increase compared with GBP $(\mathrm{p}=0.015)$ & &
\end{tabular}

Table 2. Lipid profile of male Wistar rats following chronic carbamazepine, gabapentin and carbamazepine-gabapentin adjunctive treatment

\begin{tabular}{lllll}
\hline Treatment group & LDL $(\mathbf{m g} / \mathbf{d l})$ & HDL $(\mathbf{m g} / \mathbf{d l})$ & TC $(\mathbf{m g} / \mathbf{d l})$ & TG $(\mathbf{m g} / \mathbf{d l})$ \\
\hline Control & $74.7 \pm 0.56$ & $118 \pm 0.93$ & $163 \pm 2.28$ & $782 \pm 5.79$ \\
$\mathbf{C B Z}$ & $84.4 \pm 0.64^{\beta}$ & $113 \pm 1.24^{\alpha}$ & $214 \pm 2.75^{\beta}$ & $784 \pm 2.72$ \\
$\mathbf{G B P}$ & $77.0 \pm 0.62^{\delta}$ & $118 \pm 0.72^{\mu}$ & $166 \pm 2.85^{\delta}$ & $774 \pm 1.312^{\delta}$ \\
$\mathbf{C B Z}+\mathbf{G B P}$ & $79.9 \pm 0.74^{\beta \delta \pi}$ & $115 \pm 0.93$ & $187 \pm 1.05^{\beta \delta \pi}$ & $776 \pm 1.33$ \\
\hline$\beta=$ Significant increase compared with control $(\mathrm{p}=0.005)$ & & & \\
$\delta=$ Significant decrease compared with CBZ $(\mathrm{p}=0.023)$ & & & \\
$\pi=$ Significant increase compared with GBP $(\mathrm{p}=0.040)$ & & & \\
$\alpha=$ Significant decrease compared with control $(\mathrm{P}=0.042)$ & & & \\
$\mu=$ Significant decrease compared with control $(\mathrm{P}=0.051)$ & &
\end{tabular}

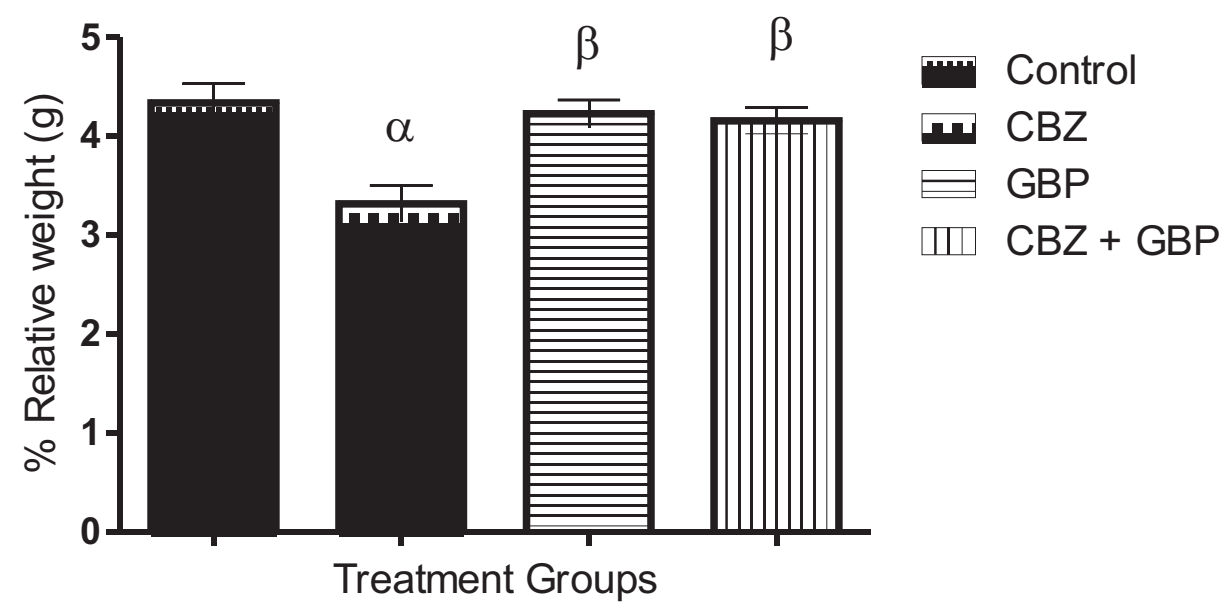

Figure 1. Effects of carbamazepine, gabapentin and carbamazepine-gabapentin combination on the percentage relative weight of the liver in male Wistar rats $\alpha$ : Significant decrease compared with control $(p=0.02)$

$\beta$ : Significant different compared with CBZ $(\mathrm{p}=0.02)$ 


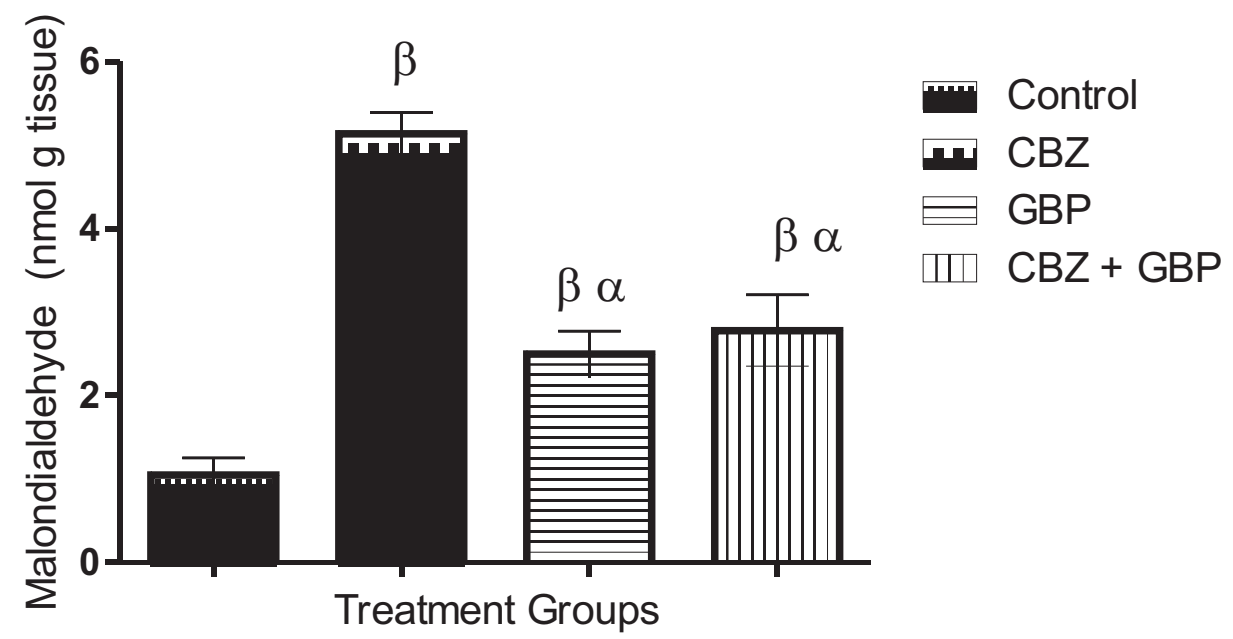

Figure 2. Effects of carbamazepine, gabapentin and carbamazepine-gabapentin adjunctive treatment on end-product of lipid peroxidation in the liver of male Wistar rats $\beta=$ Significant increase compared with control $(\mathrm{p}=0.022)$ $\alpha=$ Significant different compared with CBZ $(\mathrm{P}=0.009)$
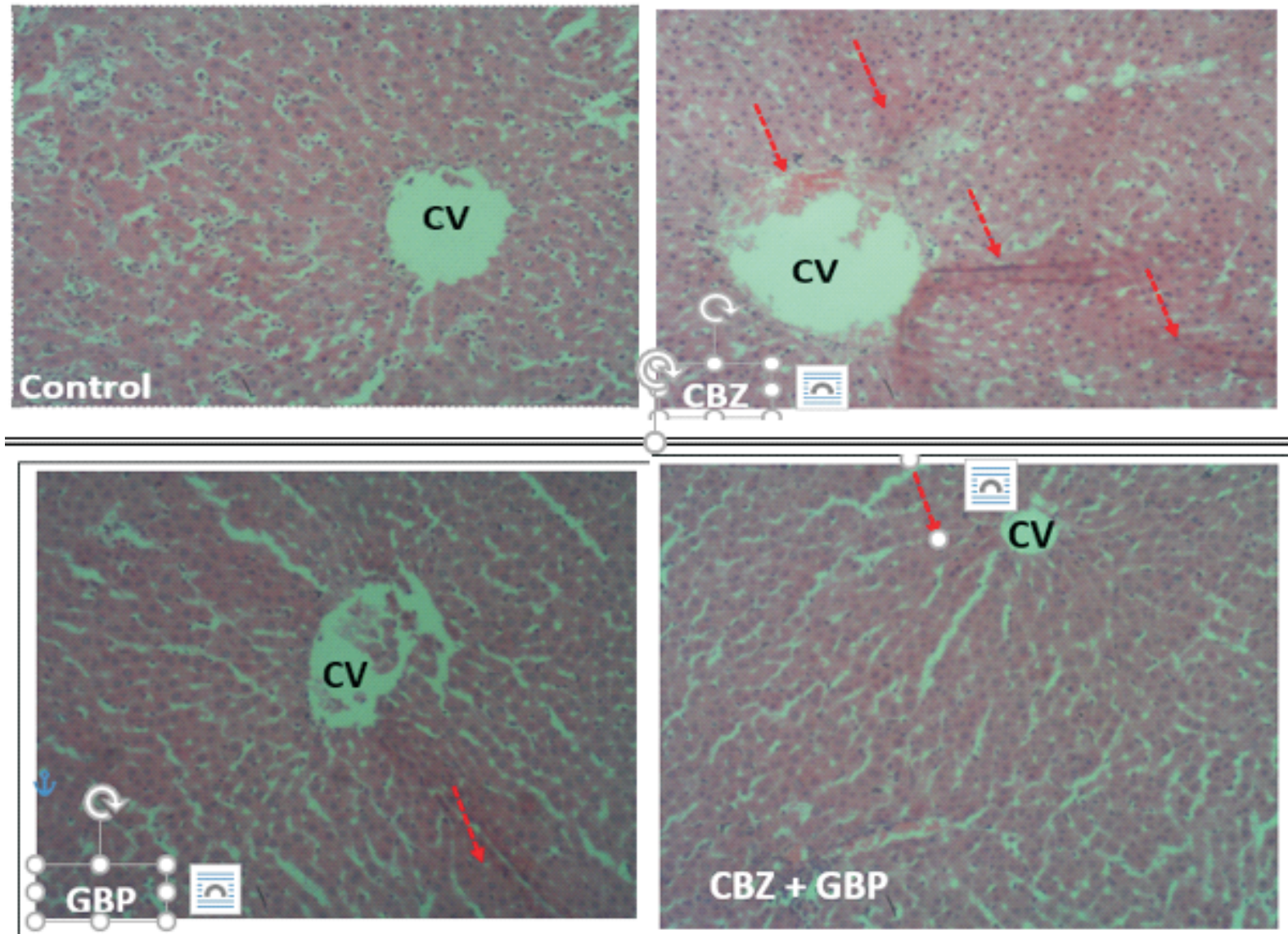

Figure 3Photomicrograph of the H\&E stained liver sections following chronic carbamazepine, gabapentin, and carbamazepine-gabapentin adjunctive treatment (Mag. X 100). 